\title{
Rancang Bangun Aplikasi E-Ticketing Travel Antar Kota Berbasis Android
}

\author{
Ciksadan', Abdul Rakhman², Indri Maharani Safira ${ }^{3}$ \\ 1,2,3 Jurusan Teknik Elektro, Program Studi Teknik Telekomunikasi Politeknik Negeri Sriwijaya \\ 1cik_sadan@yahoo.com, 2arrakhman77@gmail.cob, 3 inskiyo@gmail.com
}

\begin{abstract}
The main cause of the decline in the existence of air Cihampelas service is so expensive. So many people are switching using Cihampelas land as Travel between cities for example, as alternative means. This transport is rated more pocket friendly, because the cost offered is more affordable. But the community is still very minimal in the Kokoro which is about the availability of a successful trip. This is due to the provision of tickets that are still conventional. Therefore, by utilizing technology officials in the current communication, the author is interested to create a travel reservation system application that can run in a smartphone. This app will only be devoted to Android-based smartphones. The creation of this app uses Android Studio with Java as its main programming language. The application also uses the PHP Framework and MySQL databases with servers that are online. With this application, prospective Jeti can Kokoro about accurate travel related from the time, route, village TARIFF i.e. make a reservation and payment can be made in a grip anytime and anywhere.
\end{abstract}

Keywords: Android, Travel, E-Ticket, QR-Code, Web Server

\begin{abstract}
Abstrak
Penyebab utama menurunnya eksistensi jasa angkutan udara adalah tarifyang begitu mahal. Sehingga banyak masyarakat yang beralih menggunakan angkutan darat seperti Travel Antar Kota misalnya, sebagai sarana alternatif lainnya. Transportasi ini dinilai lebih ramah kantong, karena biaya yang ditawarkan lebih terjangkau. Akan tetapi masyarakat masih sangat minim dalam mendapatkan informasi mengenai ketersediaan tiket Travel itu sendiri. Hal ini disebabkan karena penyediaan Tiket yang masih bersifat konvensional. Oleh karena itu dengan memanfaatkan kemajuan Teknologi Informasi Komunikasi saat ini, penulis tertarik untuk membuat suatu aplikasi sistem reservasi tiket travel yang bisa berjalan dalam sebuah smartphone. Aplikasi ini hanya akan dikhususkan pada smartphone berplatform Android saja. Pembuatan aplikasi ini mengunakan Android Studio dengan Java sebagai bahasa pemrograman utamanya. Aplikasi ini juga menggunakan framework PHP dan database MySQL dengan Server yang bersifat online. Dengan adanya aplikasi ini, calon penumpang bisa mendapatkan informasi yang akurat terkait travel mulai dari jadwal, rute, tarif hingga melakukan pemesanan dan pembayaran yang dapat dilakukan dalam gengaman kapan saja dan dimana saja.
\end{abstract}

Kata Kunci: Android, Travel, E-Ticket, QR-Code, Web Server

\section{PENDAHULUAN}

Keinginan masyarakat untuk memperoleh kemudahan dalam melakukan berbagai macam kegiatan telah mendorong pesatnya kemajuan teknologi. Terutama pada teknologi komputer dan telekomunikasi seperti internet dan mobile device yang mana keduanya sudah tidak dapat lagi dipisahkan dengan kehidupan 
masyarakat saat ini. Keduanya telah mengubah pola pikir dan cara hidup masyarakat kebanyakan. Hal ini selaras dengan banyaknya pemanfaatan teknologi ini untuk berbagai bidang misalnya dalam bidang e-commerce.

E-commerce sendiri sebenarnya memiliki banyak jenis dalam penerapannya. Salah satu penerapan dari e-commerce adalah e-ticketing. E-ticketing merupakan suatu proses dimana pelanggan dapat melakukan pembelian tiket melalui internet[1]. Konsep ini dapat diterapkan untuk segala jenis tiket, salah satunya yaitu pada tiket travel antar kota. Penerapan E-ticketing pada perusahaan travel antar kota dapat memudahkan calon penumpang dalam melakukan pemesanan dan pembayaran tiket. Selain itu, calon penumpang juga dapat mengetahui semua jenis informasi terkait dengan ketersediaan tiket travel, mulai dari jadwal kebrangkatan, rute perjalanan, hingga biaya yang dibutuhkan.

Untuk mempermudah masyarakat dalam mengakses layanan ini, maka aplikasi ini akan diimplementasikan kedalam mobile device berbasis Android. Pemilihan Platform Android didasari dari segi jumlah penggunanya. Berdasarkan survey yang dilakukan pada mei 2013, minat masyarakat terhadap Android meningkat sebesar $71 \%$. Hal ini juga didukung dengan fakta yang ada, bahwa pada tahun 2018 pengguna android saat ini sudah mencapai angka 378 pengguna[2]. Karena aplikasi ini merupakan aplikasi yang dibuat oleh penulis, maka penulis memberi nama pada aplikasi tersebut yaitu Aplikasi Marvel.

\section{METODE PENELITIAN}

Penelitian ini merupakan suatu perancangan aplikasi yang menggunakan metode Waterfall dalam mengembangkan Aplikasi E-Ticketing Travel Antar Kota. Metode Waterfall merupakan suatu proses pengembangan perangkat lunak berurutan, di mana kemajuan dipandang sebagai terus mengalir ke bawah (seperti air terjun) melewati fase-fase perencanaan, pemodelan, implementasi (konstruksi), dan pengujian[3]. Perancangan aplikasi ini menggunakan XAMPP dan Android Studio sebagai pemrogramnya dengan menggunkan beberapa bahasa pemrograman seperti MySql,HTML,PHP,JavaScript dan CSS.

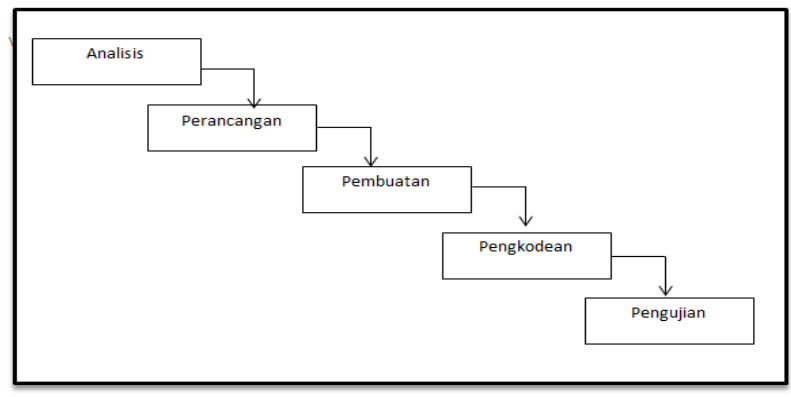

Gambar 1. Kerangka Kerja Pengembangan Sistem Waterfall

a. Analisa: Pada tahap ini penulis, merumuskan apa saja yang dibutuhkan pada perkembangan teknologi saat ini untuk mendapatkan solusi dari permasalahan yang ada. 
b. Perancangan: Tahap perancangan ini meliputi komponen komponen pendukung aplikasi untuk pembuatan aplikasi.

c. Pembuatan: Pada tahap ini penulis mulai membuat aplikasi berdasarkan desain aplikasi yang telah dibuat, dan juga memasukan data yang akan digunakan pada aplikasi ini.

d. Pengkodean: Pada tahap ini penulis mulai memasukan kode program, agar aplikasi yang dibuat dapat bekerja sesuai dengan perintah yang diinginkan. Pada tahap ini terjadi proses yang cukup panjang untuk memastikan bahwa aplikasi yang dibuat tidak error dan dapat digunakan dengan baik.

e. Pengujian: Pada tahap ini penulis mencoba aplikasi yang telah dibuat dengan mengambil data dari berbagai Agent Travel untuk memastikan bahwa aplikasi yang dibuat ini sudah berjalan dengan baik dan benar.

\section{ANALISA DAN PEMBAHASAN}

Pada penelitian ini menghasilkan sebuah aplikasi yang berbasis android. Karena saat ini hampir semua kalangan masyarakat menggunakan layanan internet untuk mendapatkan informasi, oleh sebab itu maka dibuatlah aplikasi yang bernama aplikasi MARVEL. Aplikasi ini sendiri berfungsi untuk membantu melakukan proses reservasi tiket travel antar kota. Perancangan aplikasi ini bertujuan agar calon penumpang lebih mudah dalam mendapatkan tiket travel tanpa harus mendatangi loket penjualan itu sendiri. Perancangan dan pembuatan desain dari aplikasi E-Ticketing Travel Antar Kota berbasis Android ini menggunakan diagram. Diagram yang digunakan pada tahap ini adalah flowchart activity diagram dan blok diagram.

\subsection{Blok Diagram}

Blok diagram sistem merupakan salah satu bagian terpenting dalam perancangan aplikasi. Dari blok diagram dapat diketahui prinsip kerja sistem secara keseluruhan, sehingga dapat difungsikan sebagai prinsip kerja dari rancangan suatu aplikasi[4].

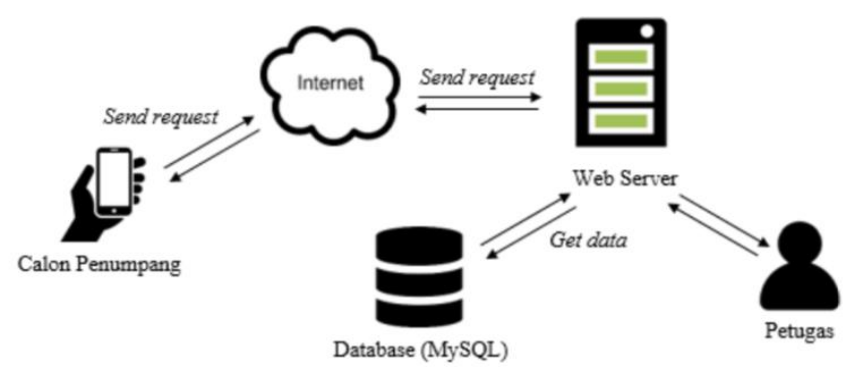

\subsection{Flowchart Activity}

Gambar 2. Blok Diagram Sistem

Flowchart activity diagram adalah pemodelan perangkat lunak yang menunjukkan alur kontrol atau aliran objek dengan penekanan pada urutan dan kondisi aliran[5]. 
a. User

Flowchart Activity User merupakan sebuah diagram dengan simbol-simbol grafis yang menyatakan prosedur sistem secara logika pada bagian user.

4. Admin

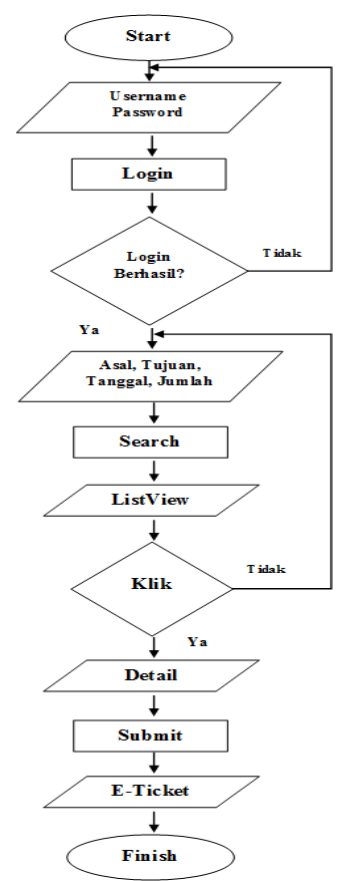

Gambar 3. Blok Diagram Sistem

Flowchart Activity Admin merupakan sebuah diagram dengan simbol-simbol grafis yang menyatakan prosedur sistem secara logika pada bagian admin.

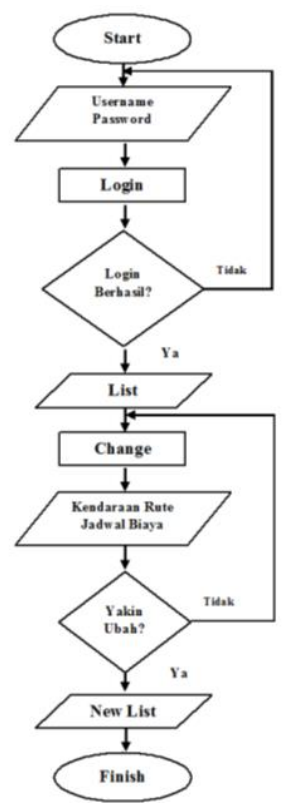

Gambar 4. Flowchart Activity Admin

Rancang Bangun Aplikasi E-Ticketing Travel Antar Kota Berbasis Android (Ciksadan) |154 


\subsection{Tampilan dari halaman aplikasi MARVEL}

\section{a. Tampilan Register User}

Pada halaman ini kita diminta untuk menginput data diri sesuai form yang telah disediakan. Pendaftaran ini bertujuan untuk memperoleh sebuah Akun yang mana nantinya akun tersebut dapat digunakan untuk Login kedalam Aplikasi Marvel. Tampilan Register User dapat dilihat pada gambar dibawah ini :

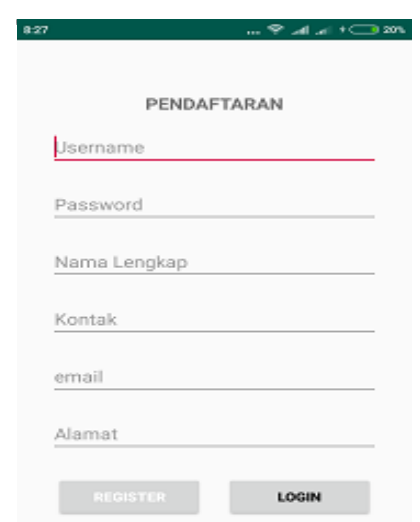

Gambar 5. Halaman Registrasi User

b. Tampilan Login User

Untuk bisa masuk kedalam aplikasi ini, kita diminta untuk memasukan Username dan juga Password yang telah terverifikasi melalui pendaftaran sebelumnya. Berikut merupakan Tampilan Login User :

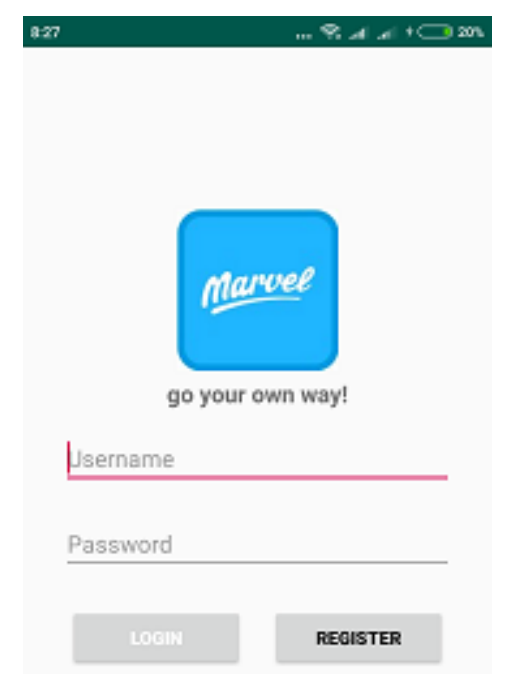

Gambar 6. Halaman Login User

c. Tampilan Aplikasi Marvel

Tampilan Aplikasi Marvel terbagi menjadi tiga buah fragment yaitu Ticket, History, dan Profile. 
Jurnal Riset Sistem Informasi Dan Teknik Informatika (JURASIK)

Volume (4) Juli 2019, pp 142-150

ISSN: 2527-5771/EISSN: 2549-7839

http://tunasbangsa.ac.id/ejurnal/index.php/jurasik

1) Tampilan Ticket

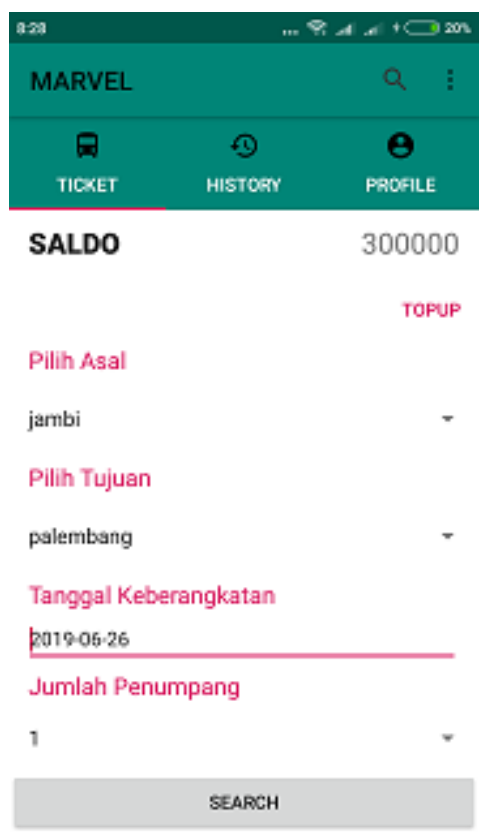

Gambar 7. Halaman Ticket

Pada halaman ini user diminta untuk memasukan asal, tujuan, tanggal keberangkatan dan juga jumlah penumpang. Selanjutnya ketika button Search di klik, sistem akan menampilkan list perjalanan yang tersedia.

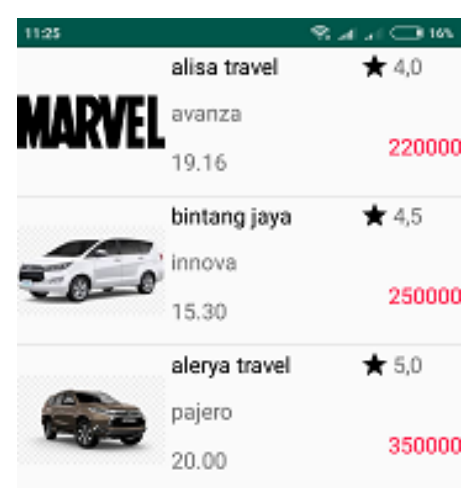

Gambar 8. Halaman Perjalanan 
Tampilan Konfirmasi Pembayaran dibutuhkan untuk melanjutkan pemesanan tiket, dimana kita diminta untuk mengkonfirmasi pesanan dengan cara melakukan pembayaran menggunakan sistem saldo elektronik. Marvel Cash akan otomatis terpotong sesuai dengan nominal pembayaran yang telah dilakukan.

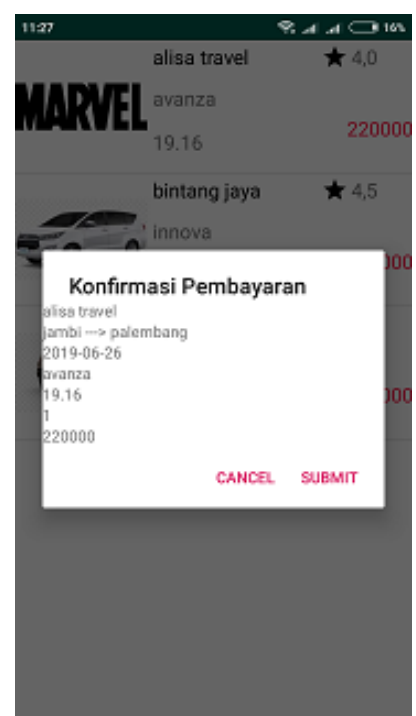

Gambar 9. Konfirmasi Pembayaran

\section{2) Tampilan History}

Halaman history adalah halaman yang menampilkan riwayat pembelian tiket yang telah dilakukan oleh user. Dimana pada halaman ini juga E-Ticket kita disimpan dalam bentuk QR-Code. Selain itu pada halaman ini kita juga dapat memberikan rating untuk perjalanan yang telah usai dilakukan.

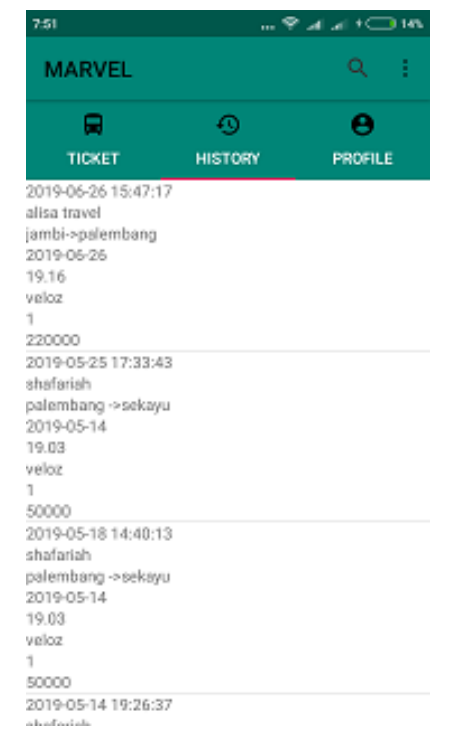

Gambar 10. Halaman History
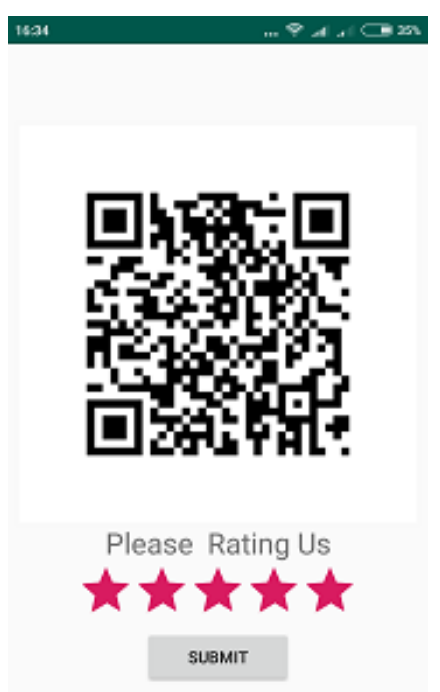

Rancang Bangun Aplikasi E-Ticketing Travel Antar Kota Berbasis Android (Ciksadan) |157 
Jurnal Riset Sistem Informasi Dan Teknik Informatika (JURASIK)

Volume (4) Juli 2019, pp 142-150

ISSN: 2527-5771/EISSN: 2549-7839

http://tunasbangsa.ac.id/ejurnal/index.php/jurasik

c) Tampilan Profile

Tampilan Profile adalah halaman yang menampilkan data diri kita sebagai user aplikasi.

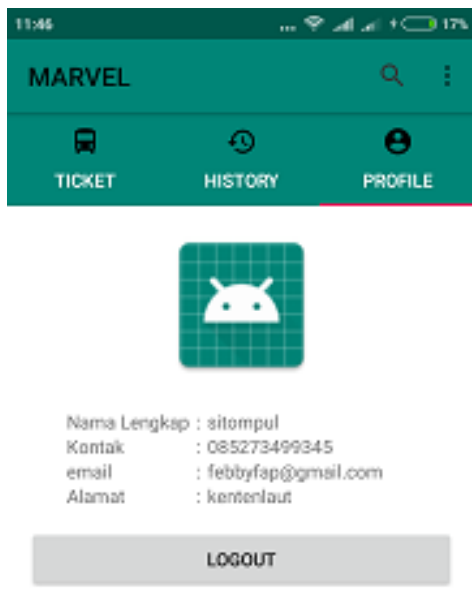

Gambar 12. Detail Halaman Ticket

\subsection{Tampilan dari halaman Web Admin}

Gambar 13 merupakan halaman localhost yang bertindak sebagai web services. Localhost adalah server lokal yang ada padai komputer. Localhost adalah hostname dari komputer itu sendiri. Localhost dapat diakses ketika ada web server yang berjalan. Locallhost ini berisi table-tabel yang digunakan untuk membuat aplikasi tersebut.

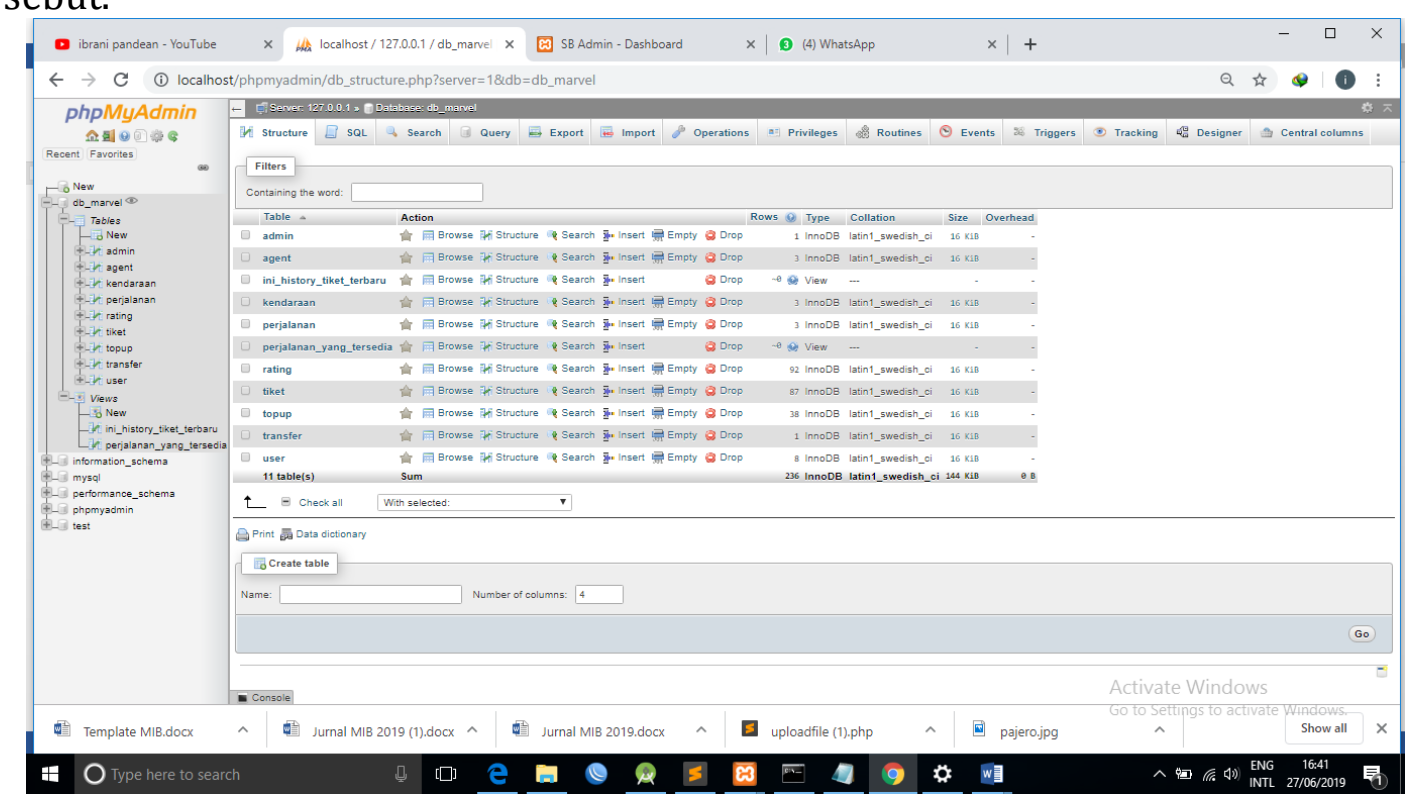

Gambar 13. Halaman Admin 


\subsection{Pengujian Fungsional dari Setiap Halaman}

Berikut adalah hasil pengujian fungsional dari setiap halaman yang ada pada aplikasi yaitu :

Tabel 1. Hasil Pengujian Aplikasi

\begin{tabular}{|l|l|c|c|}
\hline \multirow{2}{*}{ No. } & \multirow{2}{*}{ Halaman yang Diuji } & \multicolumn{2}{|c|}{ Hasil Pengujian } \\
\cline { 3 - 4 } & & Berhasil & Gagal \\
\hline 1. & Registrasi & $\mathrm{V}$ & - \\
\hline 2. & Login & $\mathrm{V}$ & - \\
\hline 3. & Menu Ticket & $\mathrm{V}$ & - \\
\hline 4. & List View Perjalanan Tersedia & $\mathrm{V}$ & - \\
\hline 5. & Konfirmasi Pembayaran & $\mathrm{V}$ & - \\
\hline 6. & Menu History & $\mathrm{V}$ & - \\
\hline 7. & Rating & $\mathrm{V}$ & - \\
\hline 8. & Menu Profile & $\mathrm{V}$ & - \\
\hline 9. & Notifikasi & $\mathrm{V}$ & - \\
\hline 10. & Logout & & \\
\hline
\end{tabular}

\section{KESIMPULAN}

Pada penelitian kali ini menghasilkan sebuah aplikasi yang dapat membantu melakukan proses reservasi tiket travel. Aplikasi ini sendiri dibuat oleh penulis dan diberi nama aplikasi MARVEL. Aplikasi ini memudahkan calon penumpang dalam mendapatkan tiket tanpa harus datang ke loket penjualan. Aplikasi ini memberikan informasi mengenai ketersediaan tiket travel, mulai dari jadwal keberangkatan, rute perjalanan, biaya yang dibutuhkan hingga pembelian tiket secara online.

\section{REFERENCES}

[1] Mahadika, Putra Rama. 2017. Pengukuran Tingkat Penerimaan Sistem E-Ticket Di Taman Margasatwa Ragunan Menggunakan Model Unified Theory of Acceptance and Use of Technology

[2] Inggrid, Lunden. 2013. Android Continues To Strom The Smartphone Market. Diakses pada https://techcrunch.com/tag/new-york/Desember 2018.

[3] Westi Yulia, Yasdinul Huda"Analisis Kualitas Layanan Jaringan Internet WiFi.Id Menggunakan Parameter QoS" Vol. 7, No. 1, Maret 2019 E - ISSN: 2302-3295

[4] Wahyu, K dan Mulyani. 2013. Aplikasi Location Based Service (LBS) Taman Mini Indonesia Indah (TMII) Berbasis Android. Seminar Nasional Aplikasi Teknologi Informasi 2013, 13-18

[5] Budiyanto, A. 2016. Pengantar Algoritma dan Pemrograman. Diakses pada http://www.academia.edu/download/39149229/Pengantar_Algoritma_dan_Pemrograman_1. pdf. 26 Desember 2018. 